\title{
Physical and Social Condition of Rehabilitated Spinal Cord Injury Patients in Japan: A Long-term Review
}

\author{
A. Nakajima, $M D,{ }^{1}$ S. Honda, $\mathrm{MD}^{2}$ \\ Division of Rehabilitation Medicine, ${ }^{1}$ Chubu Rohsai Hospital, ${ }^{2}$ Kantoh Rohsai \\ Hospital, 10-6 Kohmei-1-chohme, Minatoku, Nagoya 455, Fapan.
}

\section{Summary}

In 1983, 28 Rohsai Hospitals in Japan cooperated to study 926 spinal cord injury (SCI) patients to reveal the problems of their rehabilitation. Fifty per cent complained of poor physical condition and were anxious about their health. In addition to complications rising from the SCI, the morbidities of heart disease, diabetes mellitus, liver disease, hypertension and CVA were higher than the fapanese average. It was noted that 1) $44 \%$ of tetraplegic patients were confined to living in their home. 2) Ageing exerted a serious influence upon daily life. 3) Crutch gait for patients with paraplegia was not practical. It was also shown that utilisation of automobiles played an important role in extending social activities. For SCI patients, especially those with tetraplegia, it was very difficult to find employment. The rate of employment was only $30 \%$ in all and $46 \%$ of these were self-employed. Key words: Rehabilitated SCI patients; Physical condition; Social condition.

In recent years social conditions concerning disabled people have changed markedly in Japan, and some changes have also been seen in SCI therapy. The purpose of this study was to clarify the physical and social problems of rehabilitated SCI patients, especially any change after rehabilitation.

\section{Material and methods}

In 1983, 28 Rohsai Hospitals in this joint study group carried out a questionnaire investigation into 30 to $50 \mathrm{SCI}$ patients who were arbitrarily chosen from the discharges from each hospital for the last 20 years. The data from the investigation was microcomputer analysed. Of the 926 subjects 859 were male and 67 were female. The average age was 45 years (16 to 73 years). The number over 40 years was $66^{\circ}$ o , and over 50 years $38^{\circ}{ }_{0}$. The level of the paralysis was indicated by the lowest spinal segment of effective muscles; 105 patients had complete cervical lesions; 44 from $\mathrm{T} 1$ to $\mathrm{T} 5 ; 127 \mathrm{~T} 6$ to $\mathrm{T} 10 ; 322 \mathrm{~T} 11$ to $\mathrm{L} 1$; and 54 below L2. Two hundred and forty nine patients were incomplete: 134 cervical, 98 thoracic or lumbar, and 17 doubtful. The level of paralysis by age is 
Table I Age distribution. Total $=926$

\begin{tabular}{ccrrrrr}
\hline Year & $<19$ & $20-29$ & $30-39$ & $40-49$ & $50<$ & Total \\
\hline C & 5 & 22 & 25 & 27 & 26 & 105 \\
T1-T5 & 2 & 4 & 16 & 9 & 13 & 44 \\
T6-T10 & 1 & 18 & 30 & 32 & 46 & 127 \\
T11-L1 & 1 & 24 & 58 & 115 & 124 & 322 \\
L2- & 0 & 4 & 16 & 12 & 22 & 54 \\
Incomp. & 2 & 19 & 57 & 56 & 115 & 249 \\
? & 0 & 4 & 6 & 10 & 5 & 25 \\
& & & & & & \\
Total & 11 & 95 & 208 & 261 & 351 & 926 \\
\hline
\end{tabular}

Table II SCI duration. Total $=926$

\begin{tabular}{crrrrrrrr}
\hline Year & C & T1-T5 & T6-T10 & T11-L1 & L2- & Incomp. & ? & Total \\
\hline $1>$ & 0 & 0 & 1 & 0 & 0 & 9 & 1 & 11 \\
$2>$ & 4 & 2 & 6 & 10 & 1 & 28 & 1 & 52 \\
$5>$ & 42 & 8 & 35 & 42 & 17 & 54 & 6 & 204 \\
$10>$ & 32 & 12 & 26 & 65 & 12 & 65 & 3 & 215 \\
$10<$ & 26 & 21 & 59 & 204 & 23 & 92 & 13 & 438 \\
$?$ & 1 & 1 & 0 & 1 & 1 & 1 & 1 & 6 \\
Total & 105 & 44 & 127 & 322 & 54 & 249 & 25 & 926 \\
\hline
\end{tabular}

shown in Table I. Forty seven per cent had their injury over 10 years previously. As is shown in Table II, many of the patients with tetraplegia were injured less than 5 years ago, and more than half of the patients with paraplegia were injured 5 years or more.

\section{Results}

\section{Physical condition}

Four hundred and eighty nine patients $\left(52^{\circ}{ }_{0}\right)$ complained of being unwell, among whom 192 patients had complications. The number of patients with a poor physical condition increased as they became older, $61 \%$ of patients of 50 years and over. By the level of the paralysis the number of patients with a poor physical condition was greater in paretic patients and in patients in the T11 to L1 group, and this tendency was similarly seen if the age of the subjects was limited to below 40 years. In relation to the duration of the SCI, the number of patients with a poor physical condition was smallest in the group of 2 to 5 years after injury. The chief complaint was a feeling of poor health in 192 patients; others had vague complaints, such as being easily fatigued, sleeplessness, headache, etc.

\section{Morbidities}

The morbidities according to the subjects' age and the level of paralysis is shown in Table III; compared with the average morbidities of the Japanese nation in 1963. 
Table III Morbidities by age and paralysis level.

\begin{tabular}{|c|c|c|c|c|c|c|c|c|c|}
\hline & \multirow[b]{2}{*}{ Total } & \multicolumn{5}{|c|}{ Age } & \multicolumn{3}{|c|}{ Level of paralysis } \\
\hline & & $\begin{array}{l}\text { year } \\
<19\end{array}$ & $\begin{array}{c}\text { year } \\
20 \sim 29\end{array}$ & $\begin{array}{c}\text { year } \\
30 \sim 39\end{array}$ & $\begin{array}{c}\text { year } \\
40 \sim 49\end{array}$ & $\begin{array}{l}\text { year } \\
50<\end{array}$ & $\begin{array}{l}\text { Tetra- } \\
\text { plegia }\end{array}$ & $\begin{array}{l}\text { Para- } \\
\text { plegia }\end{array}$ & Incomp. \\
\hline Hypertension & $\begin{array}{c}7.6 \\
(2.00)\end{array}$ & $\begin{array}{c}0 \\
(0.03)\end{array}$ & $\begin{array}{c}0 \\
(0.12)\end{array}$ & $\begin{array}{c}2.4 \\
(0.80)\end{array}$ & $\begin{array}{c}7.3 \\
(3.31)\end{array}$ & $\begin{array}{l}13.4 \\
(10.1)\end{array}$ & 1.0 & 9.7 & 5.6 \\
\hline CVA & $\begin{array}{c}0.5 \\
(0.00)\end{array}$ & $\begin{array}{c}0 \\
(0.01)\end{array}$ & $\begin{array}{c}0 \\
(0.01)\end{array}$ & $\begin{array}{c}0 \\
(0.02)\end{array}$ & $\begin{array}{l}0.8 \\
(0.19)\end{array}$ & $\begin{array}{l}0.9 \\
(1.16)\end{array}$ & 0 & 0.4 & 1.2 \\
\hline $\mathrm{DM}$ & $\begin{array}{c}2.9 \\
(0.53)\end{array}$ & $\begin{array}{c}0 \\
(0.01)\end{array}$ & $\begin{array}{l}2.1 \\
(0.11)\end{array}$ & $\begin{array}{l}0.5 \\
(0.17)\end{array}$ & $\begin{array}{l}2.7 \\
(0.73)\end{array}$ & $\begin{array}{l}4.8 \\
(1.84)\end{array}$ & 1.0 & 4.0 & 1.6 \\
\hline Heart disease & $\begin{array}{c}2.7 \\
(0.73)\end{array}$ & $\begin{array}{c}0 \\
(0.01)\end{array}$ & $\begin{array}{c}0 \\
(0.04)\end{array}$ & $\begin{array}{l}1.0 \\
(0.18)\end{array}$ & $\begin{array}{c}2.7 \\
(0.63)\end{array}$ & $\begin{array}{c}4.6 \\
(2.79)\end{array}$ & 1.9 & 2.4 & 3.6 \\
\hline Liver disease & $\begin{array}{c}3.3 \\
(0.32)\end{array}$ & $\begin{array}{c}0 \\
(0.03)\end{array}$ & $\begin{array}{c}0 \\
(0.08)\end{array}$ & $\begin{array}{l}1.4 \\
(0.17)\end{array}$ & $\begin{array}{l}5.0 \\
(0.66)\end{array}$ & $\begin{array}{c}4.3 \\
(0.94)\end{array}$ & 0 & 4.2 & 2.8 \\
\hline $\begin{array}{l}\text { Gastro-intesinal } \\
\text { disease }\end{array}$ & $\begin{array}{l}3.3 \\
(0.75)\end{array}$ & $\begin{array}{c}0 \\
(0.14)\end{array}$ & $\begin{array}{l}2.1 \\
(0.41)\end{array}$ & $\begin{array}{l}5.8 \\
(0.75)\end{array}$ & $\begin{array}{l}8.8 \\
(1.24)\end{array}$ & $\begin{array}{l}10.3 \\
(2.00)\end{array}$ & 3.8 & 6.8 & 10.8 \\
\hline Respirat. disease & $\begin{array}{l}1.5 \\
(0.37)\end{array}$ & $\begin{array}{c}0 \\
(0.14)\end{array}$ & $\begin{array}{c}0 \\
(0.07)\end{array}$ & $\begin{array}{l}0.5 \\
(0.09)\end{array}$ & $\begin{array}{l}1.9 \\
(0.38)\end{array}$ & $\begin{array}{l}2.3 \\
(0.83)\end{array}$ & 3.8 & 0.9 & 2.0 \\
\hline Others & 6.4 & 0 & 6.3 & 5.8 & 5.0 & 8.0 & 7.6 & 4.2 & 10.0 \\
\hline No. of objects & 926 & 11 & 95 & 208 & 261 & 351 & 105 & 447 & 249 \\
\hline
\end{tabular}

() average morbidities of Japanese nation in 1963

Table IV Urine condition. According to the way of urination.

\begin{tabular}{lccccc}
\hline & $\begin{array}{c}\text { Indwell. } \\
\text { catheterisation }\end{array}$ & $\begin{array}{c}\text { Intermitt. } \\
\text { catheterisation }\end{array}$ & $\begin{array}{c}\text { Crede } \\
\text { voiding }\end{array}$ & $\begin{array}{c}\text { Almost } \\
\text { normal }\end{array}$ & Unknown \\
\hline Always cloudy & $14(14.0)$ & $9(9.1)$ & $61(10.9)$ & $4(4.1)$ & $7(9.6)$ \\
Sometimes cloudy & $51(53.0)$ & $42(42.4)$ & $205(36.5)$ & $20(20.6)$ & $14(19.2)$ \\
Cloudy in morning & $9(9.0)$ & $10(10.1)$ & $86(15.3)$ & $9(9.3)$ & $4(5.5)$ \\
Almost clean & $10(10.5)$ & $21(21.2)$ & $140(24.9)$ & $26(26.8)$ & $7(9.6)$ \\
Clean & $7(7.4)$ & $9(9.1)$ & $44(7.8)$ & $23(23.7)$ & $4(5.5)$ \\
Unknown & $4(4.2)$ & $8(8.1)$ & $26(4.6)$ & $15(15.5)$ & $37(50.7)$ \\
Total & 95 & 99 & 562 & 97 & 73 \\
\hline
\end{tabular}

() Percentage

1) Hypertension was 2.8 times and CVA was 1.6 times the average, and the incidence tended to be high in the young.

2) Diabetes mellitus was 5.5 times the average, and occurred in all groups.

3) Heart disease was 3.7 times, and liver disease was 10.3 times the average.

In relation to the level of paralysis (in those with complete paralysis), the incidence of pressure ulcers, cystitis, pyelonephritis and hypertension was higher in patients with paraplegia compared to those with tetraplegia. But we have to consider the difference of age. It was interesting that gastro intestinal disease was often seen in spinal paresed patients when compared with the many paresed patients complaining of a poor physical condition.

\section{Urological status}

The urinary condition of the patients was divided into 5 categories. About $50 \%$ of patients in the first and second appeared to have a chronic urinary tract 
Table V Pressure ulcer and motor level of paralysis. Upper is during admission and lower is after rehabilitation

\begin{tabular}{|c|c|c|c|c|c|c|c|c|c|c|}
\hline & Head & $\begin{array}{l}\text { Upper } \\
\text { limb }\end{array}$ & Back & $\begin{array}{c}\text { Sacro } \\
\text { coccyg. }\end{array}$ & Ischium & Thigh & $\begin{array}{c}\text { Lower } \\
\text { leg }\end{array}$ & Foot & $\begin{array}{c}\text { No. of } \\
\text { patients }\end{array}$ & $\begin{array}{l}\text { Total of } \\
\text { subjects }\end{array}$ \\
\hline \multirow{2}{*}{$\mathrm{C}$} & $3(2.0)$ & $3(2.9)$ & $5(4.8)$ & $62(59.0)$ & $11(10.5)$ & $6(5.7)$ & $6(5.7)$ & $17(16.2)$ & \multirow{2}{*}{$80(76.2)$} & \multirow{2}{*}{105} \\
\hline & 0 & 0 & 0 & $24(2.29)$ & $10(9.5)$ & $5(4.8)$ & $3(2.9)$ & $3(2.9)$ & & \\
\hline \multirow{2}{*}{$\mathrm{T} 1-\mathrm{T} 5$} & $3(6.0)$ & $2(4.5)$ & $3(6.8)$ & $28(63.6)$ & $6(13.6)$ & $1(2.3)$ & $6(13.6)$ & $12(27.3)$ & \multirow{2}{*}{$36(81.8)$} & \multirow{2}{*}{44} \\
\hline & 0 & $1(2.3)$ & $1(2.3)$ & $17(38.6)$ & $6(13.6)$ & $4(9.1)$ & $1(2.3)$ & $6(13.6)$ & & \\
\hline \multirow{2}{*}{ T6-T10 } & $1(0)$ & $1(0.8)$ & $7(5.5)$ & $76(59.8)$ & $27(21.3)$ & $9(7.1)$ & $9(7.1)$ & $15(11.8)$ & \multirow{2}{*}{$108(85.0)$} & \multirow{2}{*}{127} \\
\hline & 0 & 0 & 0 & $40(31.5)$ & $34(26.8)$ & $9(7.1)$ & $4(3.1)$ & $8(6.3)$ & & \\
\hline \multirow{2}{*}{$\mathrm{T} 11-\mathrm{L} 1$} & 0 & $1(0.3)$ & $14(4.3)$ & $172(53.4)$ & $67(20.8)$ & $24(7.5)$ & $21(6.5)$ & $44(13.7)$ & \multirow{2}{*}{$253(78.6)$} & \multirow{2}{*}{322} \\
\hline & $1(0.3)$ & 0 & $6(1.9)$ & $63(19.6)$ & $104(32.3)$ & $18(5.6)$ & $11(3.4)$ & $38(11.8)$ & & \\
\hline \multirow{2}{*}{ L2- } & 0 & 0 & 0 & $21(38.9)$ & $2(3.7)$ & $2(3.7)$ & $3(5.6)$ & $6(11.1)$ & \multirow{2}{*}{$34(63.0)$} & \multirow{2}{*}{54} \\
\hline & 0 & 0 & 0 & $9(16.7)$ & $8(14.8)$ & $1(1.9)$ & $1(1.9)$ & $7(13.0)$ & & \\
\hline \multirow{2}{*}{ Incomp. } & $5(2.0)$ & $10(4.0)$ & $14(5.6)$ & $90(36.0)$ & $19(7.6)$ & $7(2.8)$ & $12(4.8)$ & $27(10.8)$ & \multirow{2}{*}{$127(50.8)$} & \multirow{2}{*}{250} \\
\hline & $2(0.8)$ & $5(2.0)$ & $2(0.8)$ & $31(12.4)$ & $11(4.4)$ & 0 & $10(4.0)$ & $16(6.4)$ & & \\
\hline \multirow{2}{*}{$?$} & 0 & 0 & $2(8.0)$ & $9(36.0)$ & $3(12.0)$ & $4(16.0)$ & $3(12.0)$ & $4(16.0)$ & \multirow{2}{*}{$17(68.0)$} & \multirow{2}{*}{25} \\
\hline & 0 & 0 & 0 & $7(28.0)$ & $4(16.0)$ & $3(12.0)$ & $2(8.0)$ & $3(12.0)$ & & \\
\hline \multirow{2}{*}{ Total } & $12(1.3)$ & $17(1.8)$ & $45(4.5)$ & $458(49.5)$ & $135(14.6)$ & $53(5.7)$ & $60(6.5)$ & $125(13.5)$ & \multirow[t]{2}{*}{$655(707)$} & \multirow[t]{2}{*}{926} \\
\hline & $(0.3)$ & $6(0.6)$ & $9(1.0)$ & $191(20.6)$ & $177(19.1)$ & $40(4.3)$ & $32(3.5)$ & $81(8.7)$ & & \\
\hline
\end{tabular}

() Percentage 
infection. According to the level of paralysis a significant difference was not seen in completely paralysed patients, excluding the group with a lesion-who were less affected below L2. Considering the method of micturition, Crede voiding was the most popular $(57 \%)$. According to the method of micturition (as shown in Table IV), the condition of the urine using the Crede method and self-catheterisation was good. A change of the rehabilitated subject's urinary condition was improved in $17 \%$ and worsened in only $8 \%$. Initial urological management exerted a great influence on the subsequent progress of patients.

\section{Pressure ulcers}

Incidence of pressure ulcers in subjects through their SCI life was $71 \%$, being $62 \%$ during hospital stay and $44 \%$ after their rehabilitation. According to the levels of paralysis the incidence of pressure ulcers was highest in the group T6 to T10 $(85 \%)$; that in the completely paralysed patients exceeding $75 \%$ at any level-excluding those below L2. The ulcers most frequently occurred in the sacro-coccygeal region. In the ischial region, they occurred in patients with lesions from $\mathrm{T} 6$ to $\mathrm{L} 1$, and only in this region was the incidence (after rehabilitation) higher than that during the admission period (Table V). Many patients had pressure ulcers which recurred after rehabilitation at the same site as during the initial hospital admission. The incidence of reactivation was $52 \%$ in the ischial region. $76 \%$ of the ulcers occurred in the sacro-coccygeal region after rehabilitation was reactivation.

\section{Social condition}

\section{Activities of daily living}

Basic activity of daily living was evaluated into five groups, as shown in Figure $1 ; 1$ ) confined to bed $5 \%$;) mainly in bed, allowed up only for meals $7 \%$; 3 ) confined to the house $14 \%$; 4 ) able to go out occasionally $34 \%$; 5) frequently able to go out $34 \%$; 6) doubtful $7 \%$.

According to the level of motor paralysis in completely paralysed patients, those in group 1 or 2 who were confined to bed most of the time made up $28 \%$ (cervical spinal cord); 18\% (T1 to T5), and a few at a lower level. Patients who could go out in groups 4 or 5 were $52 \%$ (cervical), $73 \%$ (T11 to L1), and about the same number of patients at $\mathrm{T} 1$ to $\mathrm{T} 10$. As patients became older, the ability of daily living deteriorated, especially after 50 years, Figure 1. After rehabilitation, patients whose daily activities were increased constituted $37 \%$ shown as $(+)$ in Figure 1, and those with diminished activity $19 \%(-)$. Changes in each group i.e. complete tetraplegia, complete paraplegia and paresis, were shown. In patients with tetraplegia the main improvement was seen in groups 3 to 4 or 5 , and deterioration in groups 5 to 4 and 4 to 1,2 or 3 . For patients with paraplegia or paresis the main improvement was seen in groups 3 to 4 or 5 and 4 to 5 and deterioration in groups 5 to 4 . The main reason for these changes in the activities of daily living was a change of the living environment after rehabilitation. This factor often exerted a negative influence on tetraplegia and positive on paraplegia. 
Figure 1 Basic ADL

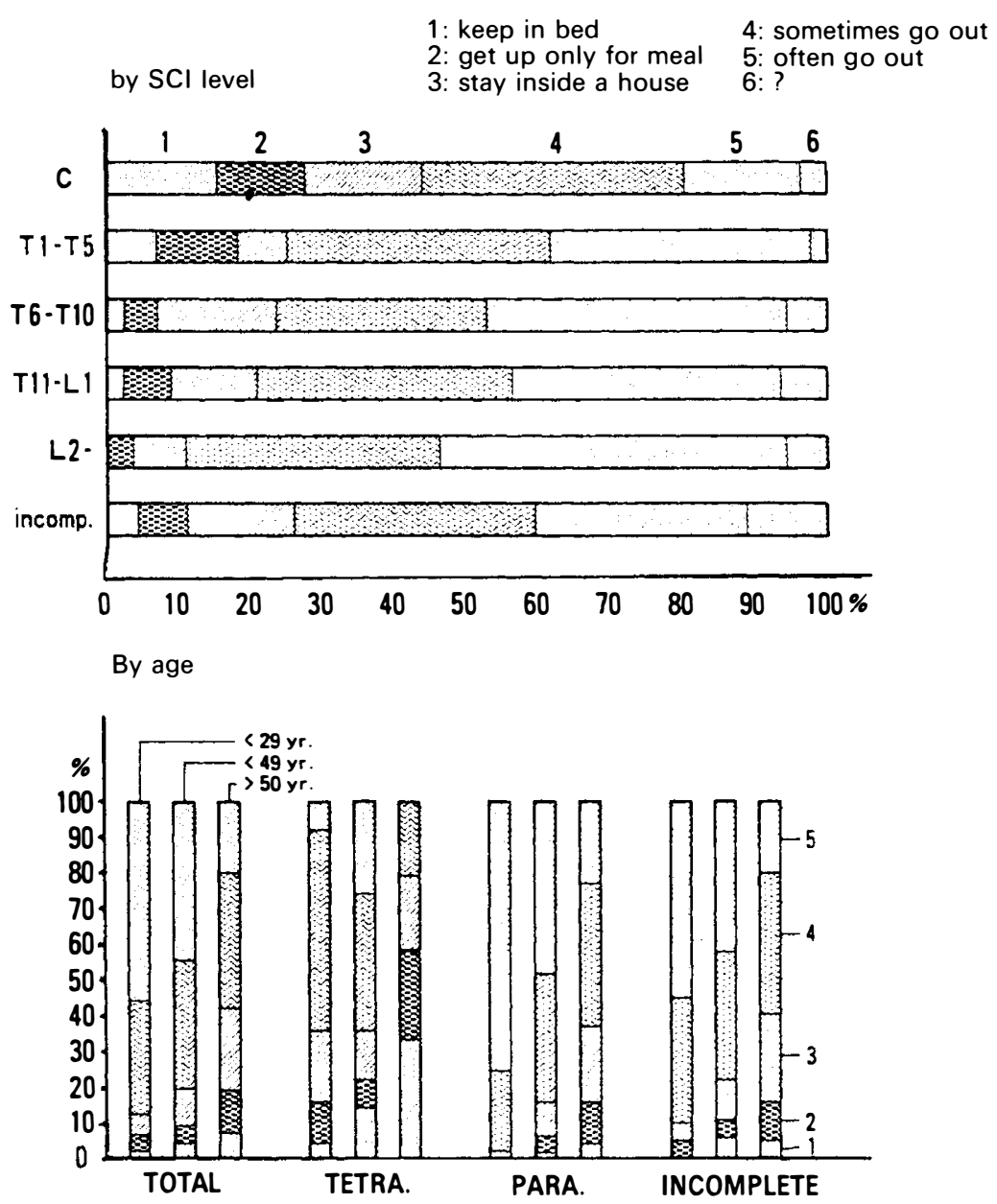

Change after rehabilitation

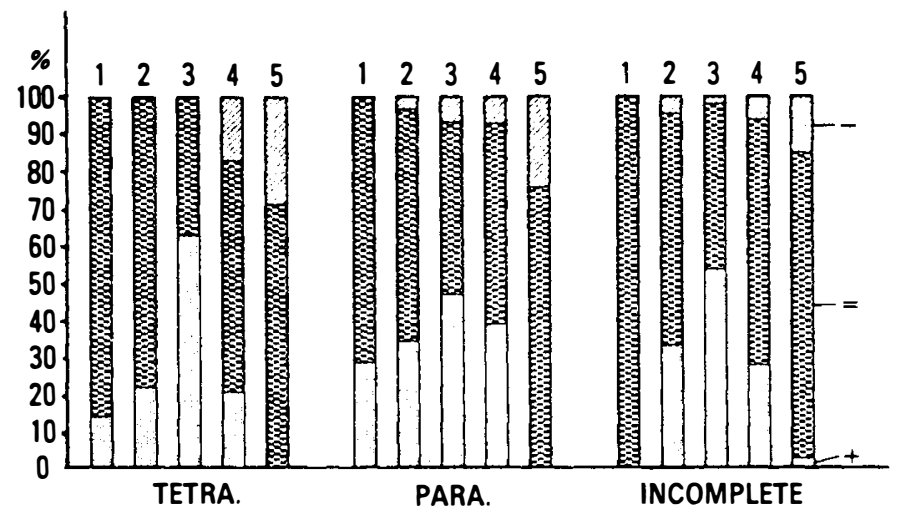


Figure 2 Independence in ADL and change af ter rehabilitation.

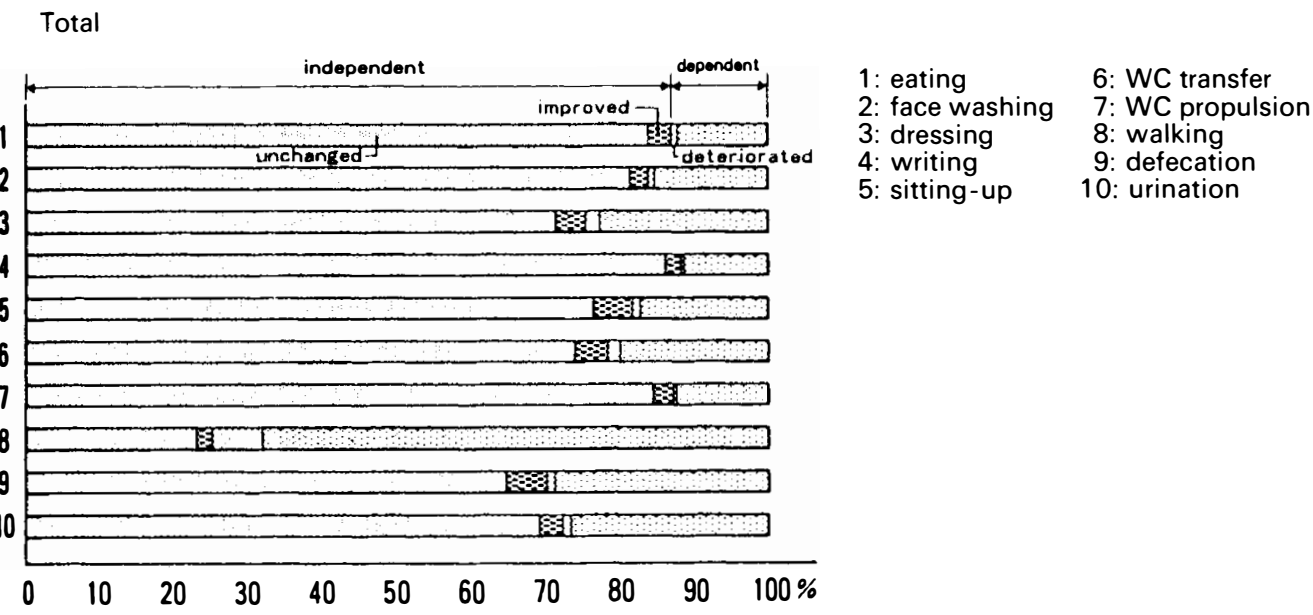

Tetraplegics

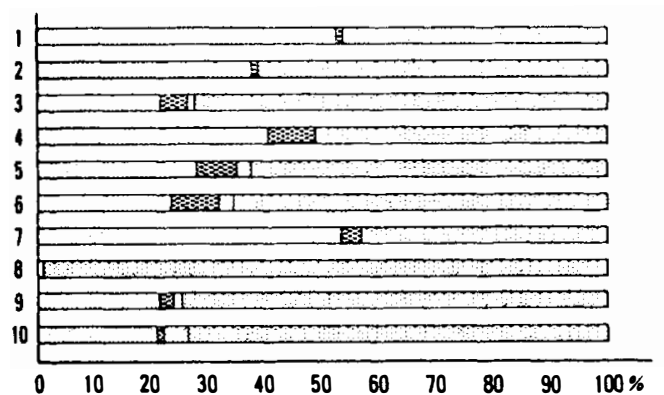

Paraplegics

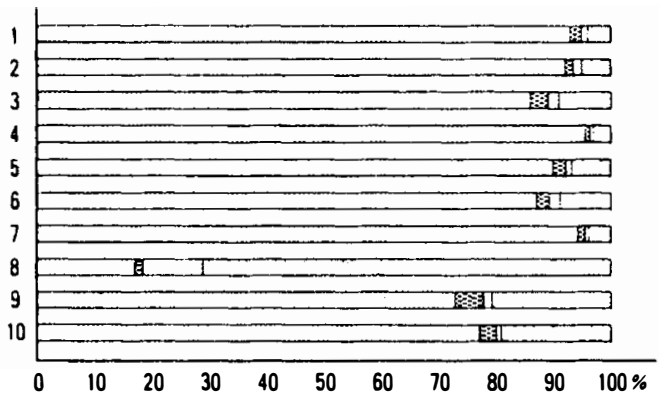

Incomplete

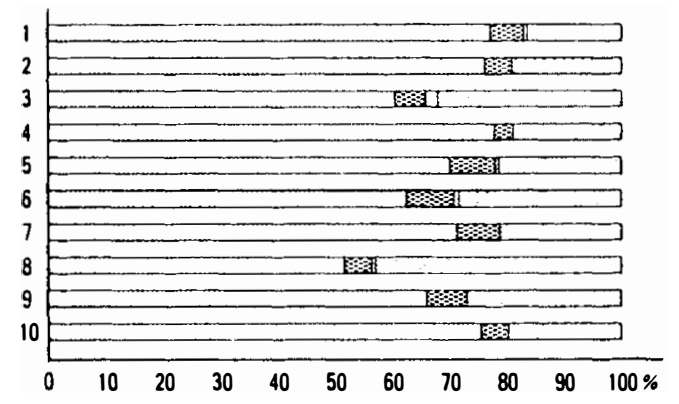


Figure 3 Hours in wheelchair (hr./day)

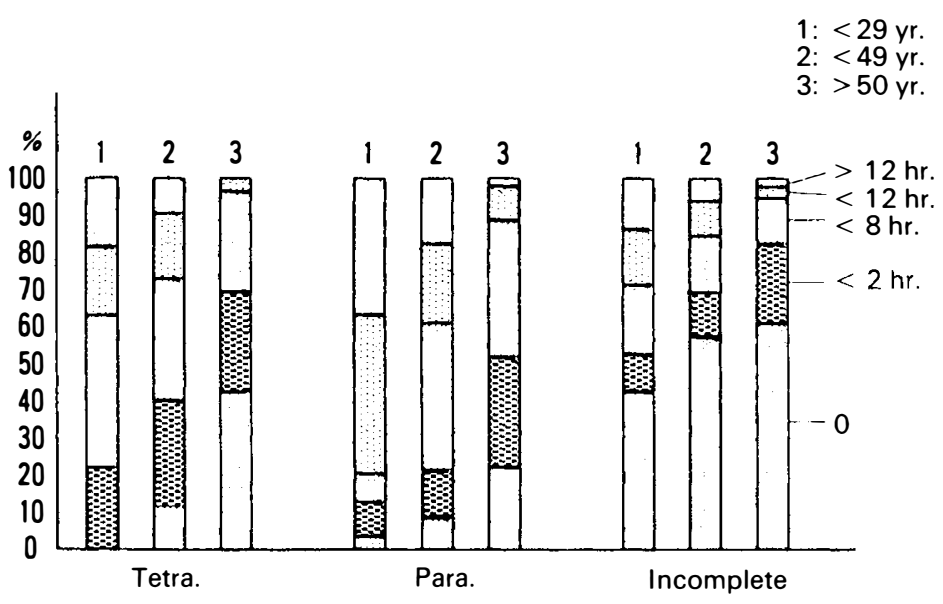

The way patients could carry out the 10 main activities of daily living, and a change of the results after rehabilitation, are shown in Figure 2. Not many changes were seen before and after rehabilitation. It was, understandably difficult for patients with tetraplegia to carry out 10 activities, and age exerted a great influence on their ability. Patients with paraplegia could carry out over $90 \%$ of the activities, but only $17 \%$ of patients could carry out crutch gait and the deterioration rate after rehabilitation was high. In Japan the wheelchair has become the main method of locomotion with a change of social environment so that the number of patients using crutches has been decreasing every year. Recently only $22 \%$ of patients used crutches on discharge and the number of patients using these after rehabilitation has been rapidly decreasing. In this study only $10 \%$ of patients with complete paraplegia were still using crutches.

Figure 3 shows the relation between an average time in a wheelchair per day and age. As patients become older the time in a wheelchair decreased. Excluding patients who could walk, the number of patients using a wheelchair only 2 hours or less a day was $43 \%$ in patients with tetraplegia, and $32 \%$ in paraplegia. However, in patients under 29 years old, the rate was $22 \%$ in patients with tetraplegia and $13 \%$ in paraplegia. On the other hand in patients over 50 years old the rate was very high; $69 \%$ in patients with tetraplegia and $52 \%$ in paraplegia.

The number of 'outing times' was considered an index of the social living ability; $39 \%$ of patients with tetraplegia, $75 \%$ of patients with paraplegia and $70 \%$ of paretic patients went out more than once a week, but $20 \%, 5 \%$ and $11 \%$ of them did not go out at all. Ninety four per cent of patients with paraplegia below 29 years old went out over 1 kilometre more than once a week and $49 \%$ every day, approximately the same level of activity in social life as healthy people (Figure 4).

Fourteen per cent of patients with tetraplegia and $58 \%$ of patients with paraplegia could drive a car, and $82 \%$ of them went out more than once a week. Ability to drive a car exerted a great influence on the social life of SCI patients. 
Figure 4 Times of outing

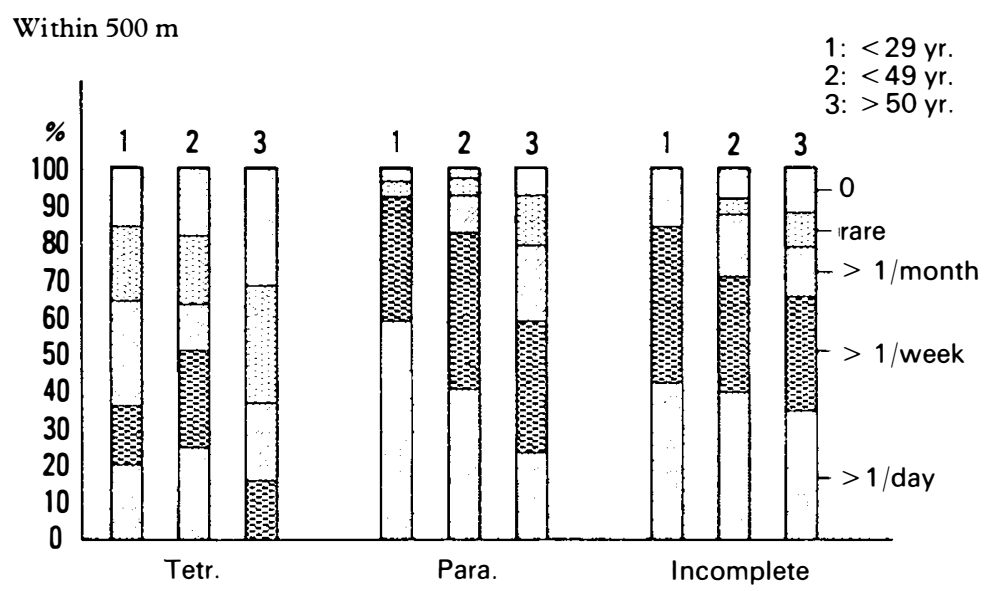

Over $1000 \mathrm{~m}$

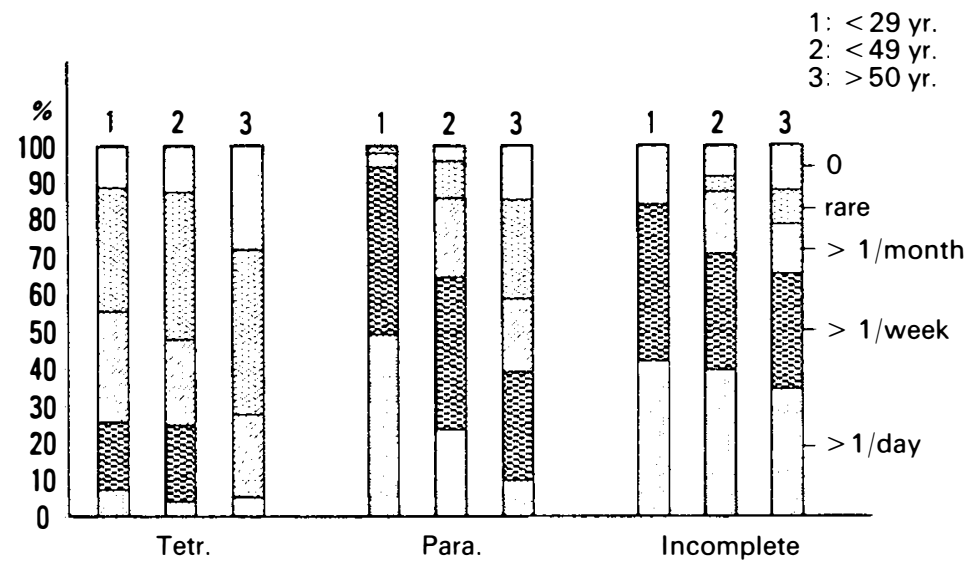

\section{Life environment}

As the structure of the Japanese house basically requires to sit on Tatamimat, it is difficult to use a wheelchair in an ordinary house. So when SCI patients return home it was necessary to consider the interior structure of a house; $43 \%$, extended the house and $44 \%$ partially rebuilt their home. Rooms requiring reconstruction were firstly the bathroom, then the washroom and bedroom; this seemed to be mainly due to the peculiarities of the structure of the average Japanese house. The number requiring extension and rebuilding in patients with tetraplegia was lower than that in patients with paraplegia in every aspect.

\section{Employment}

The number of patients with working experience after injury were $42 \%$ overall. In the case of completely paralysed patients only $11^{\circ}$ o of patients with tetra- 
Figure 5 Reason for retiring

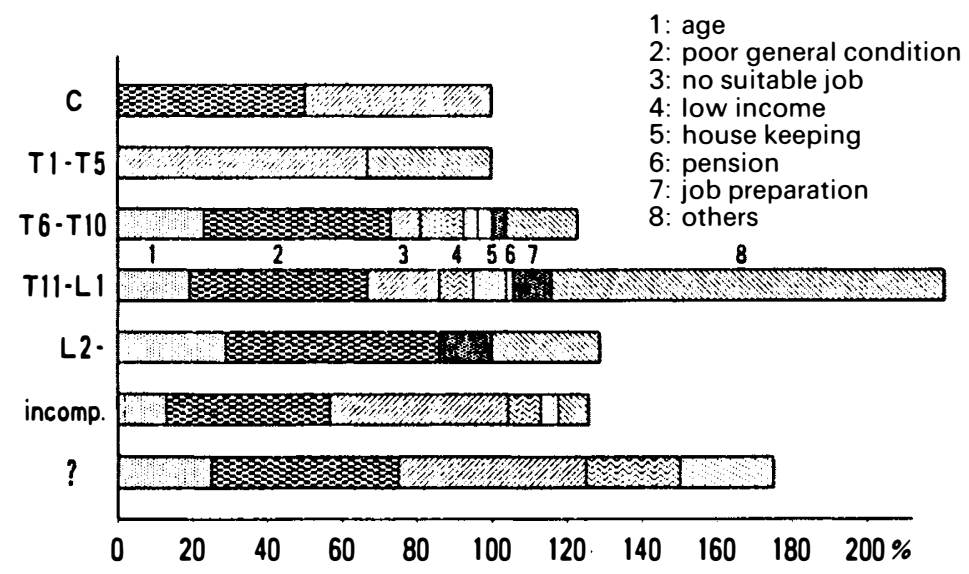

plegia, $41 \%$ at $\mathrm{T} 1$ to $\mathrm{T} 5,48 \%$ at $\mathrm{T} 6$ to $\mathrm{T} 10,51 \%$ at $\mathrm{T} 11$ to $\mathrm{L} 1,57 \%$ at below L2 and $39 \%$ of paretic patients. It is difficult in Japan for a disabled person to find employment, $30 \%$ of patients who had found employment left their job. At the time of the investigation 271 patients were working $(28 \%)$.

Concerning working conditions, $46 \%$ were self-employed, $32 \%$ were livingout employees and $16 \%$ were working in a sheltered workshop. $58 \%$ of the whole series had no working experience after injury. 56\% gave physical reasons such as paralysis, poor physical condition and an advanced age, and $9 \%$ answered that there was no suitable work for them. The main reason they left a job that they engaged in after injury was physical, as shown in Figure 5. However, some of them answered that they had to keep the house instead of their wives or that their income was too low.

\section{Conclusions}

This study on 926 SCI patients rehabilitated from 28 Rohsai Hospitals in Japan demonstrated their long-term physical and social problems.

\section{Physical problems}

Many of the SCI patients felt uneasy about their physical condition and had several vague complaints. It was doubtful if these vague complaints were directly related to SCI and only $37 \%$ of them had complications. Concerning the tendency to complications, urinary tract infection and pressure ulcers did occur frequently, but it was noted that hypertension, CVA, diabetes mellitus, heart disease and liver disease was more frequent than that of the average in the Japanese nation. It is possible to imagine a causal relation between liver disease and blood-transfusion following injury, also hypertension and renal dysfunction. However, the relation between these high morbidity diseases and SCI is a problem that requires further study.

Urinary tract infection was observed in about half the subjects. Most were long-standing cases that did not undergo suitable treatment at the first stage 
after injury. Subjects whose urinary condition changed after rehabilitation were relatively few, i.e. improved $17 \%$, worsened $9 \%$. This fact signifies the importance of early treatment. The incidence of pressure ulcers reached $78 \%$ in all. About half occurred during the admission period, and relapsed at the same site after rehabilitation. Seventy five per cent of pressure ulcers (after rehabilitation), in the sacro-coccygeal region were relapses, and in patients in group T1 to T10 (who had relatively high ADL), the relapses were most frequently seen. This fact signifies the importance of initial care.

\section{Social problems}

\section{Problems of $A D L$}

Life for about $25 \%$ of SCI patients (especially the $45 \%$ of patients with tetraplegia) was limited to the house and they did not go out. The reason for this appears to be that the structure of the Japanese house and the social environment were not always improved sufficiently to be suitable for life in a wheelchair. On the other hand young patients with paraplegia (especially those who can drive a car) enjoy great social activity.

The time in a wheelchair and the number of outings were considered an index of the ability of daily living. Ability of daily living of SCI patients over 50 years old frequently deteriorated. Ageing seemed to cause much more serious deterioration of SCI patient's ability than that of healthy people but the reason was not clear. The advanced age of a seriously disabled person and their attendant family has become a problem in Japan.

Also in Japan the use of crutches for patients with paraplegia has been decreasing every year, $(10 \%$ in this study), and most use them in order to maintain function. Now crutch-gait training for patients with paraplegia in medical rehabilitation is in a state of confusion in Japan.

Change of life environment after rehabilitation exerted (as seen from the viewpoint of activity of daily living), a negative influence on patients with tetraplegia and a positive effort on patients with paraplegia. This fact indicated the difficulty for patients with tetraplegia to maintain the same life environment in their own houses as in the hospital.

\section{Life environment}

In Japan, the structure of the average house prevents severely disabled patients (especially patients who depend on a wheel chair), from rehabilitation. In this study $87 \%$ of patients extended or reconstructed their houses. However, it is not always possible for them to live in a house suitable for a wheelchair life because there are so many rooms which should be altered and there is not enough financial aid from the government.

\section{Employment}

It is difficult for a seriously disabled person, such as a SCI patient, to find employment in Japan. Under the law for promoting the employment of disabled 
persons, the rate of employment for patients with paraplegia has gradually increased; however, it is extremely difficult for patients with tetraplegia to find employment. It seems also a problem that $46 \%$ of working subjects $(29 \%$ of the whole series) are self-employed. Reasons why SCI patients do not work or find it is difficult for them to find employment are mainly physical problems. However, some patients explained that an earned income was low compared with an annuity for a disabled person; perhaps this was because many of the subjects in this series were injured in an industrial accident. Thus, there are still many problems awaiting solution, such as improved facilities of employment for a disabled person, an annuity system and a means of motivating a disabled person's will to work.

\section{References}

Nakajima A, Yoshida I, Mizuno M, Sakai M 1982 The follow up study of physical condition of rehabilitated paraplegics-On relation to crutch gait. The fapanese fournal of Rehabilitation Medicine 19:75-81.

JENIK F, KUHN W, ZACK GA 1982 Social and vocational reintegration of paraplegic and tetraplegic patients in Switzerland. Paraplegia 20:65-70.

Sutton RA, Bentley M, Castree B, Mattinson R, Pattinson J, Smith R 1982 Review of the social situation of paraplegic and tetraplegic patients rehabilitated in the Hexham regional spinal injury unit in the north of England over the past four years. Paraplegia 20:71-79.

LANG HD, DurR W, Hoffmann J, KOETh R 1980 Post-clinical follow-up of spinal patients through domestic check-ups. Paraplegia 18:140-144.

BEDBROCK GM 1981 The care and management of spinal cord injuries. Springer Verlag, New York. 